\title{
Preliminary evaluation of a new initiative to centralize colorectal cancer care during the COVID-19 epidemic in Shanghai, China: a retrospective study
}

\author{
Rui Liu ${ }^{1 \#}$, Xuejing Yu ${ }^{1 \#}$, Xueyun Zeng1,2\#, Zheng Wang ${ }^{3,4}$, Danqing Zhou ${ }^{1}$, Zhongchen Liu ${ }^{3,4}$, Feng Liu ${ }^{3,4}$, \\ Chengle Zhuang $^{3,4}$, Ying Zhuang ${ }^{3}$, Ji Zhang ${ }^{5}$, Peiqin Niu ${ }^{5,6}$, Ben Yan ${ }^{7}$, Rui Zhi ${ }^{7}$, Jiyu Li ${ }^{1,8}$, Jiaoling Huang', \\ Huanlong Qin ${ }^{1,3,4}$
}

${ }^{1}$ Tongji University Cancer Center, Shanghai Tenth People's Hospital of Tongji University, Shanghai, China; ${ }^{2}$ Department of Medical Affairs, Shanghai Chest Hospital, Shanghai Jiao Tong University, Shanghai, China; ${ }^{3}$ Colorectal Cancer Center, Shanghai Tenth People's Hospital of Tongji University, Shanghai, China; ${ }^{4}$ Department of Gastrointestinal Surgery, Shanghai Tenth People's Hospital of Tongji University, Shanghai, China; ${ }^{5}$ Medical Service Section, Shanghai Tenth People's Hospital of Tongji University, Shanghai, China; ${ }^{6}$ Department of Gastroenterology, Shanghai Tenth People's Hospital of Tongji University, Shanghai, China; ${ }^{7}$ Department of Infrastructure, Shanghai Tenth People's Hospital of Tongji University, Shanghai, China; ${ }^{8}$ Geriatric Oncology Center, Huadong Hospital, Fudan University, Shanghai, China; ${ }^{9}$ School of Public Health, Shanghai Jiao Tong University School of Medicine, Shanghai, China

Contributions: (I) Conception and design: All authors; (II) Administrative support: None; (III) Provision of study materials or patients: None; (IV) Collection and assembly of data: R Liu, X Yu, Z Wang; (V) Data analysis and interpretation: X Zeng, D Zhou, J Zhang, F Liu; (VI) Manuscript writing: All authors; (VII) Final approval of manuscript: All authors.

\#These authors contributed equally to this work.

Correspondence to: Dr. Jiyu Li. Tongji University Cancer Center, Shanghai Tenth People's Hospital of Tongji University, 301 Yanchang Middle Road, Jing'an District, Shanghai 200000, China. Email: Leejiyu@sina.com; Dr. Jiaoling Huang. School of Public Health, Shanghai Jiao Tong University School of Medicine, 227 Chongqing South Road, Shanghai 200025, China. Email: jiaoling_huang@sina.com; Professor Huanlong Qin. Tongji University Cancer Center, Shanghai Tenth People's Hospital of Tongji University, 301 Yanchang Middle Road, Jing'an District, Shanghai 200000, China. Email: huanlong_qin@live.cn.

Background: A novel colorectal cancer center (CCC) was developed in the Shanghai Tenth People's hospital of Tongji University during the COVID-19 epidemic. In this study, we aimed to evaluate the CCC model in terms of three aspects.

Methods: This retrospective study used data from the Shanghai Tenth People's hospital patient databases. The research hypothesis was that the CCC reduces preoperative waiting time (PWT), length of hospital stay (LOS), and costs of hospitalization, without reducing the quality of surgery. Thus, we compared the time, cost, and quality between March 1 to December 31, 2019, and March 1 to December 31, 2020. Descriptive and inferential analyses of patient demographic characteristics, time, postoperative outcomes, and inpatient costs were conducted.

Results: A total of 965 hospitalizations for colorectal cancer (CRC) were identified-415 in 2019 and 550 in 2020. In the CCC, PWT declined by 26.2 hours $(\mathrm{P}<0.01)$. Patients in the CCC express group only needed to wait for 24.5 hours before undergoing surgery, with a shorter LOS than the normal group $(\mathrm{P}<0.01)$. None of the patients had any symptoms of COVID-19 or were high-risk COVID-19 contacts, and the incidence of immediate postoperative complications was low. The mean total inpatient cost (TIC) for all patients with CRC was 78,309.824 Chinese Yuan in 2020, which was slightly lower than that in 2019.

Conclusions: This study found that the centralized management model for CRC care could help patients save the PWT, LOS and costs of hospitalization during the COVID-19 epidemic.

Keywords: Colorectal cancer (CRC); coronavirus disease 2019 (COVID-19); colorectal surgery; integrated care; health economics 
Submitted Dec 03, 2021. Accepted for publication Jan 18, 2022.

doi: $10.21037 /$ atm-21-7030

View this article at: https://dx.doi.org/10.21037/atm-21-7030

\section{Introduction}

Colorectal cancer (CRC) is among the leading causes of death worldwide and represents a major public health problem $(1,2)$. In China, this problem is particularly serious due to the increased incidence of CRC. According to the Global Cancer Observatory, CRC ranks second highest among all cancers; in 2020, 555,477 patients were newly diagnosed with CRC in China and 286,162 patients with CRC died (3). Surgery is the foundation of curative therapy for CRC, and timely access to surgery is crucial (4-6). Several large retrospective cohort studies have demonstrated worse outcomes with surgical delay, such as tumor progression, increased complications, and recurrence, all of which were associated with worse overall survival (7-10).

The emergence of coronavirus disease 2019 (COVID-19) placed a great deal of strain on both the healthcare system and the population $(11,12)$. Healthcare providers saw traditional surgical practices have been questioned or suspended. The safety of patients and healthcare workers had to be considered, particularly during aerosol-generating medical procedures such as endoscopy and laparoscopic surgery. Moreover, the health-seeking behaviors of patients may have changed because of fears that hospitals are highrisk areas for COVID-19 infection; thus, patients may have delayed presentation until particularly prominent symptoms develop (13).

The challenges faced by hospital leadership, including the prevention or control the COVID-19 epidemic and saving sick patients by treating the disease, are of unprecedented importance in this time of crisis. Therefore, hospital infrastructure should be reorganized to allow for a safe flow of patients within the hospital, maintaining social distance as an institutional practice. These required changes present both challenges as well as opportunities.

It is well known that the diagnosis and treatment of CRC are multidisciplinary, and involve very complex procedures $(14,15)$. The centralized management model is a method of providing complex procedural care to the population, with regulations or policies ranging from unregulated free flows to single-center centralization (16). Centralization is a way to improve the efficiency of hospital services (17). However, to date, no specific guidance has been issued on how to best modify CRC service provision during the COVID-19 pandemic. There is an opportunity to restructure existing resources to establish a colorectal cancer center (CCC), making use of the centralized management model to deliver integrated healthcare to improve CRC service capability and optimize service efficiency. In addition, an exceptional express model formed in the CCC based on the integration of resources and service may provide patients with a faster and better medical experience.

This study aimed to assess the ability of a hospital's centralized and team-based model of care to adapt to the pandemic by evaluating the wait times before surgery and the length of hospital stay (LOS) for CRC patients, compared with a similar period in the previous year. We also sought to evaluate the feasibility of the express model, including in terms of postoperative quality improvement and cost reduction, compared with the traditional surgery model.

We present the following article in accordance with the STROBE reporting checklist (available at https://atm. amegroups.com/article/view/10.21037/atm-21-7030/rc).

\section{Methods}

\section{Data sources and main measures}

The research hypothesis was that CCCs could reduce the preoperative waiting time (PWT), LOS, and cost of hospitalization without reducing the quality of the surgery. Thus, to assess each of these factors, we analyzed the following three aspects: time, cost, and quality. We compared the outcomes from March 1 to December 31, 2019, with those from March 1 to December 31, 2020 (comparison 1, denoted as year*). We then selected the data from Dr. Liu's team for a comparison across the same two time periods because this team was the first team to participate in the CCC pilot (comparison 2, denoted as year $\left.{ }^{\dagger}\right)$. We also compared CCC patients with non-CCC patients (comparison 3, denoted as CCC), and express patients with normal patients (comparison 4, denoted as express).

Descriptive analyses and significance tests were performed for each comparison, and the significant covariates were then included in the linear regression models, which estimated the net effects of year*, year ${ }^{\dagger}$, 
CCC, and express. This process allowed us to be relatively confident that the significant differences observed in the four comparisons outlined above did not result from other factors. The research was conducted in Shanghai, which is the largest city in China and has high-quality medical resources. The first CCC was established in the Shanghai Tenth People's Hospital of Tongii University, which is the most renowned cancer treatment institution in Shanghai, especially for CRC.

Data were extracted from patient databases of the study hospital, including the health information system, clinical information system, anesthesia information management system, and picture archiving and communication system databases. These databases were not connected automatically; thus, we used the patients' social medical insurance identification numbers as a unique identifier to connect the databases. All procedures performed in this study involving human participants were in accordance with the Declaration of Helsinki (as revised in 2013). This study has been approved by the Ethics Committee of the Shanghai Tenth People's Hospital of Tongji University (No. SHSY-IEC-4.1/20-272/01). Informed consent was obtained from all participants who took part in this study. We identified in patients with CRC using the International Classification of Diseases-10 codes in the health information system database, and obtained these inpatients' identification numbers, which we used to extract their information from the other databases. We gathered data from March to December 2020 because the CCC was not in operation prior to March 2020, and data were also gathered from the same period in 2019 for comparison, allowing us to perform the abovementioned comparisons for Dr. Liu's group (before $v s$. after), CCC $v s$. non-CCC patients, and express $v s$. normal patients.

Time, the first outcome aspect, was operationalized as PWT and LOS. PWT refers to the amount of time from hospitalization to surgery (measured in hours), and LOS refers to the length of time from hospitalization to discharge (measured in days). Quality, the second outcome dimension, was operationalized as postoperative complications, including the total number of postoperative complications and presence/absence of the most common postoperative complications (respiratory tract infection, urinary tract infection, surgical site infection, anastomotic leakage, and anastomotic bleeding), as well as surgery outcome, which was categorized as cured, improving, unhealed, death, or other. Cost, the third outcome aspect, was operationalized as the total inpatient cost (TIC), cost structure (costs of prescription drugs, consumables, testing, physician/nurse services, and other items), and patients' out-of-pocket (OOP) costs.

Additionally, we collected data on demographic variables, including gender, age, household registration, medical insurance, and complications. Medical insurance was categorized as local urban employee basic medical insurance, local urban and rural resident basic medical insurance, or basic medical insurance of another province. The surgery method variable was categorized as left hemicolectomy, right hemicolectomy, transverse colectomy, sigmoid colectomy, or radical resection of rectum.

\section{Strategies in the CCC}

\section{The centralized management model}

In China, the multidisciplinary team (MDT) concept has been widely accepted among government health authorities and hospital officials $(18,19)$. As the Cancer Center of Tongji University, the Shanghai Tenth People's hospital of Tongii University has also become the first pilot hospital for multi-disciplinary diagnosis and treatment of digestive system tumors designated by the National Health Commission of the People's Republic of China (20). Hence, this cancer center began to explore the multidisciplinary collaboration model of CRC treatment. However, this model works mainly through online consultation, and the department silos in the cancer center have not been broken down entirely.

Mature competencies among leaders and specialized multidisciplinary centers are thought to be the key factors in promoting CRC treatment. Substantial reform stake time, particularly due to the renovation of the layout of existing clinics or construction of new clinics in the limited space for expansion, which is costly and time consuming (21). Since the outbreak of COVID-19, a series of infection-prevention policies (i.e., stay-at-home orders) have been implemented, and regular outpatient visits have been postponed. The number of patients has thus decreased significantly, making it possible to rebuild the outpatient clinic layout.

At the beginning of January2020, meetings were held with all stakeholder groups, and the decision was made to create a CCC combining gastroenterology, endoscopy, general surgery, nutrition, and oncology in one location using the centralized management model. Through this model, the patient experience in the process can ultimately lead to the delivery of more timely and efficient care (22). Following a series of measures, the CCC was initiated on 
March 1, 2020.

\section{Personnel structure}

The president of the hospital, Dr. Qin, who is a CRC specialist as well as a hospital management expert, leads the CCC as the executive director of the center. An excellent endoscopist, Dr. Z Liu, with more than 10 years' experience in endoscopic submucosal dissection; and a gastrointestinal surgery specialist, Dr. F Liu, who is highly skilled in laparoscopic radical resection of CRC, both serve as the executive deputy directors of the center. A Cancer Committee, including in-hospital and external specialists in general surgery, gastroenterology, endoscopy, neurology, pathology, radiology, oncology, anesthesiology, nursing management, and primary care, was established to set standards and monitor quality.

\section{Layout design}

The construction administrators considered the effect of the layout design, such as flow direction, on the patient experience and quality of care delivered in the clinic under the epidemic prevention and control policies in effect. An outpatient-based center of excellence was set up by modifying the existing standard outpatient clinic layout. In addition to the standard consultation rooms, the related diagnostic and technology area and procedure rooms for treatment and nursing care were combined to create a "one-stop shopping" experience for patients. Blood and tissue samples can also be taken in this area and then sent to labs through a pneumatic tube system or another logistics transmission system (Figure 1). This layout design laid the foundation for sequential therapy, facilitating the achievement of improved throughput, increased patient access, and shortened LOS for patients with CRC.

\section{Diagnostic process and express group inclusion criteria} Special diagnosis and treatment processes for patients with CRC were constructed under the centralized management model (Figure 2). The HistoCore PELORIS 3 produced by Leica Biosystems was added into the procedure to achieve rapid tissue processing, and the pathology report could be obtained in 4-5 hours; this facilitated CRC diagnosis through polyps and early carcinogenesis. Moreover, patients who met the inclusion criteria, which were determined by the Cancer Committee with reference to the "Guidelines for the Preoperative System Evaluation and Treatment of Elderly in the United States", were included into an express model (Figure 3). Patients in the express model could enjoy faster endoscopic pathology, hospitalization, and preoperative examination than normal patients.

\section{Statistical analysis}

The data were processed and analyzed using R Studio, Version 1.2.1335 (RStudio, Inc.). Descriptive [mean, min., max., and standard deviation (SD)] and inferential (chi-square test and $\mathrm{F}$ test) analyses were performed for each comparison described above. Ordinary least squares regression models were used to determine which factors were significant for predicting PWT (models 1-4), LOS (models 5-8), TIC (models 9-12), cost of prescription drugs (models 13-16), cost of consumables (CC) (models 17-20), cost of testing (models 21-24), and OOP (models 25-28). After the significant covariates were identified, covariance tests were performed to test the net effects of year*, year $^{\dagger}$, CCC, and express. The threshold of statistical significance was set at $\mathrm{P}<0.05$ (two-tailed).

\section{Results}

\section{Characteristics of patients with CRC}

A total of 965 hospitalizations for CRC were identified-415 in 2019 and 550 in 2020. Most baseline patient characteristics were comparable across each pair of groups in the four comparisons. More than half of the patients in $2020(\mathrm{n}=285,51.82 \%)$ had comorbidities, which was higher than the percentage of 2019 patients with comorbidities $(\mathrm{n}=148,35.66 \%, \mathrm{P}<0.001)$, and the mean number of comorbidities was also higher in 2020 than in 2019 (0.669 \pm 0.741 vs. $0.487 \pm 0.732, \mathrm{P}<0.001)$. Age, gender, and comorbidities were similar between patients who chose the CCC and those who did not [age: $64.971 \pm 11.694 \mathrm{vs}$. $65.926 \pm 11.992, \mathrm{P}=0.878$; gender (male): $\mathrm{n}=183,59.6109 \%$ vs. $\mathrm{n}=152,62.551 \%, \mathrm{P}=0.539$; comorbidities (yes): $\mathrm{n}=150$, $48.860 \%$ vs. $\mathrm{n}=135,55.556 \%, \mathrm{P}=0.140]$. However, patients from Shanghai made up a larger percentage of the CCC group than of the non-CCC group $(\mathrm{n}=212,69.0555 \%$ vs. $\mathrm{n}=138,56.790 \%, \mathrm{P}=0.04$ ), and patients without health insurance made up a smaller percentage of the CCC group than of the non-CCC group $(\mathrm{n}=31,10.098 \%$ vs. $\mathrm{n}=41$, $16.872 \%, \mathrm{P}=0.002)$. Patients in the CCC express model were younger $(62.6 \pm 12.072$ vs. $65.8 \pm 10.273, \mathrm{P}<0.05)$ and in less serious condition (incidence of comorbidities: $37.037 \%$ vs. $53.097 \%, \mathrm{P}=0.019$; incidence of cardiovascular disease: $32.099 \%$ vs. $47.788 \%, \mathrm{P}=0.021$ ), compared with normal 


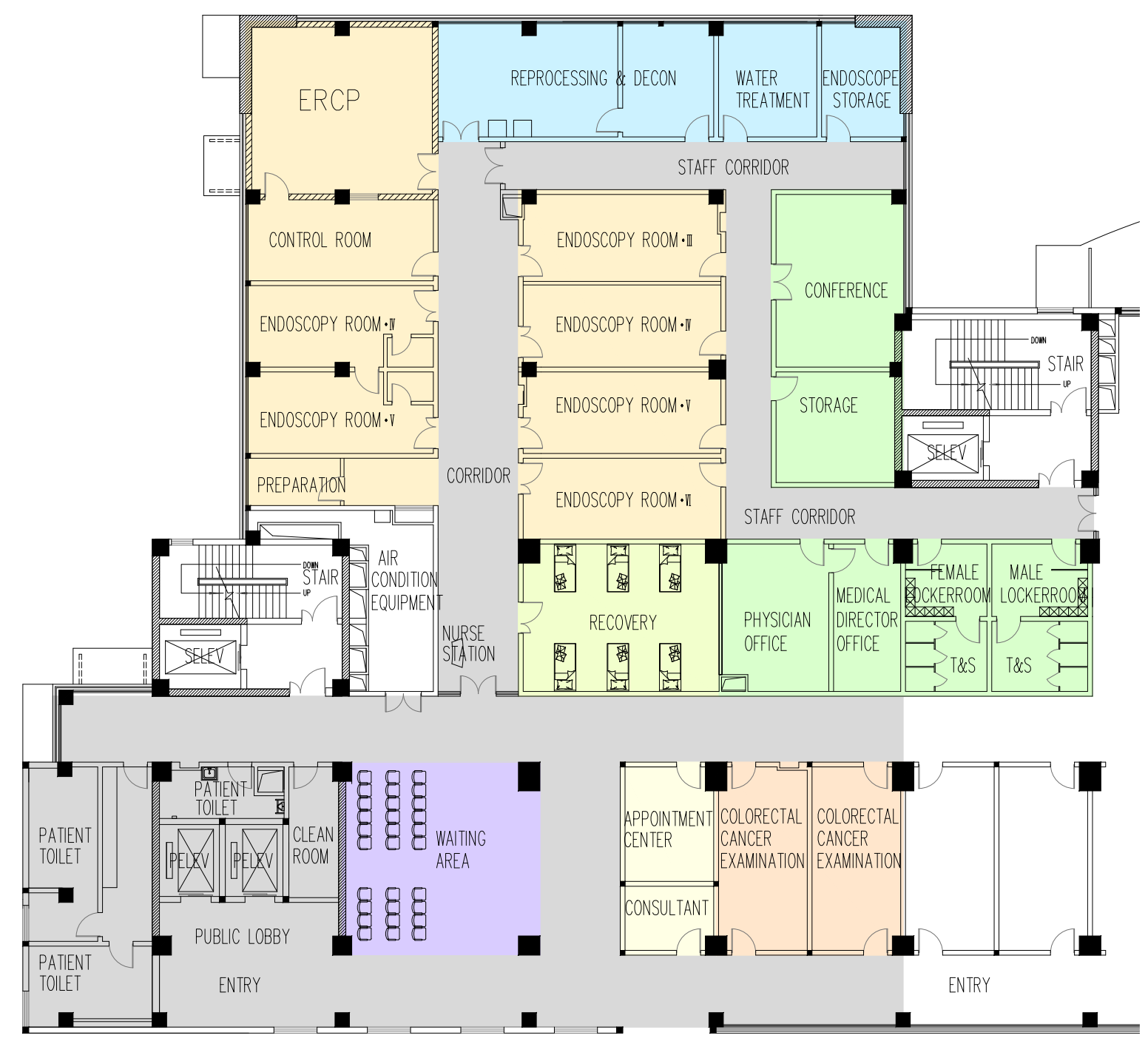

Figure 1 Layout of the colorectal cancer center. ERCP, endoscopic retrograde cholangiopancreatography.

patients (Table 1).

\section{Time comparison}

Both PWT and LOS were shorter following application of the centralized management model in the CCC (Table 2). For patients treated by the team of doctors using the centralized management model, PWT was shortened by 26.2 hours in 2020 (133.060 vs. 106.822, $\mathrm{P}=0.003$ ). For patients in the CCC-express group, the PWT was only 24.5 hours before surgery, and these patients also had a shorter LOS compared with the normal group (10.963 vs. 17.217, $\mathrm{P}<0.001)$. In the regression analysis of all factors affecting
LOS, we observed that sigmoid colectomy was a significant covariate. After controlling for this covariate, the time differences across the four comparisons did not change. This means that the net effects of year ${ }^{*}$, year ${ }^{\dagger}$, and CCC were statistically significant (Figure 4 and Table S1).

\section{Postoperative outcomes}

During the COVID-19 lockdown period, no patients had any COVID-19 symptoms or high-risk contacts. The incidence of immediate postoperative complications was low and similar across each of the four comparisons (Figure 5). Surgical outcome was also generally similar across each 


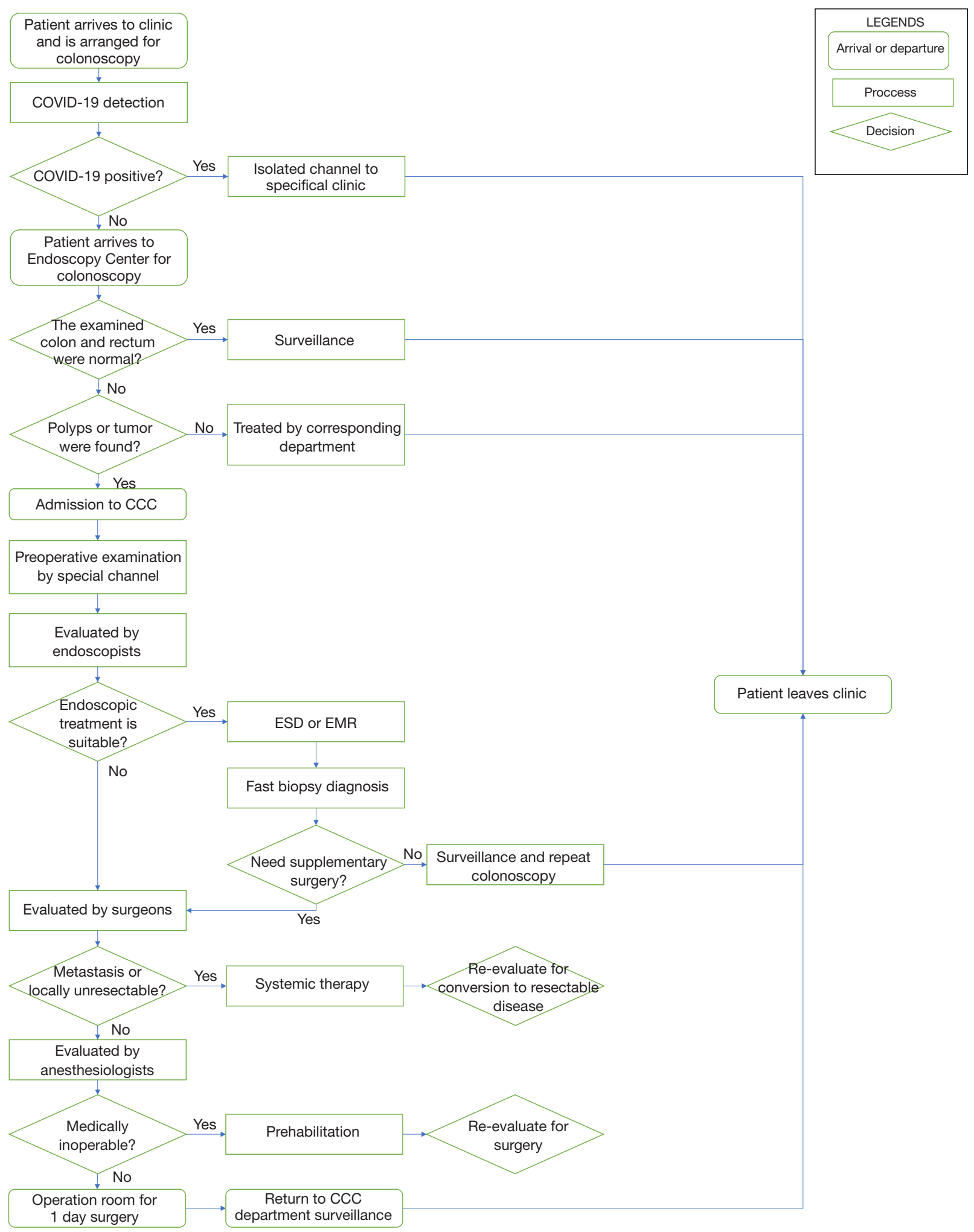

Figure 2 Diagnosis and treatment process in the CCC. COVID-19, coronavirus disease 2019; ESD, endoscopic submucosal dissection; EMR, endoscopic mucosal resection; CCC, colorectal cancer center. 


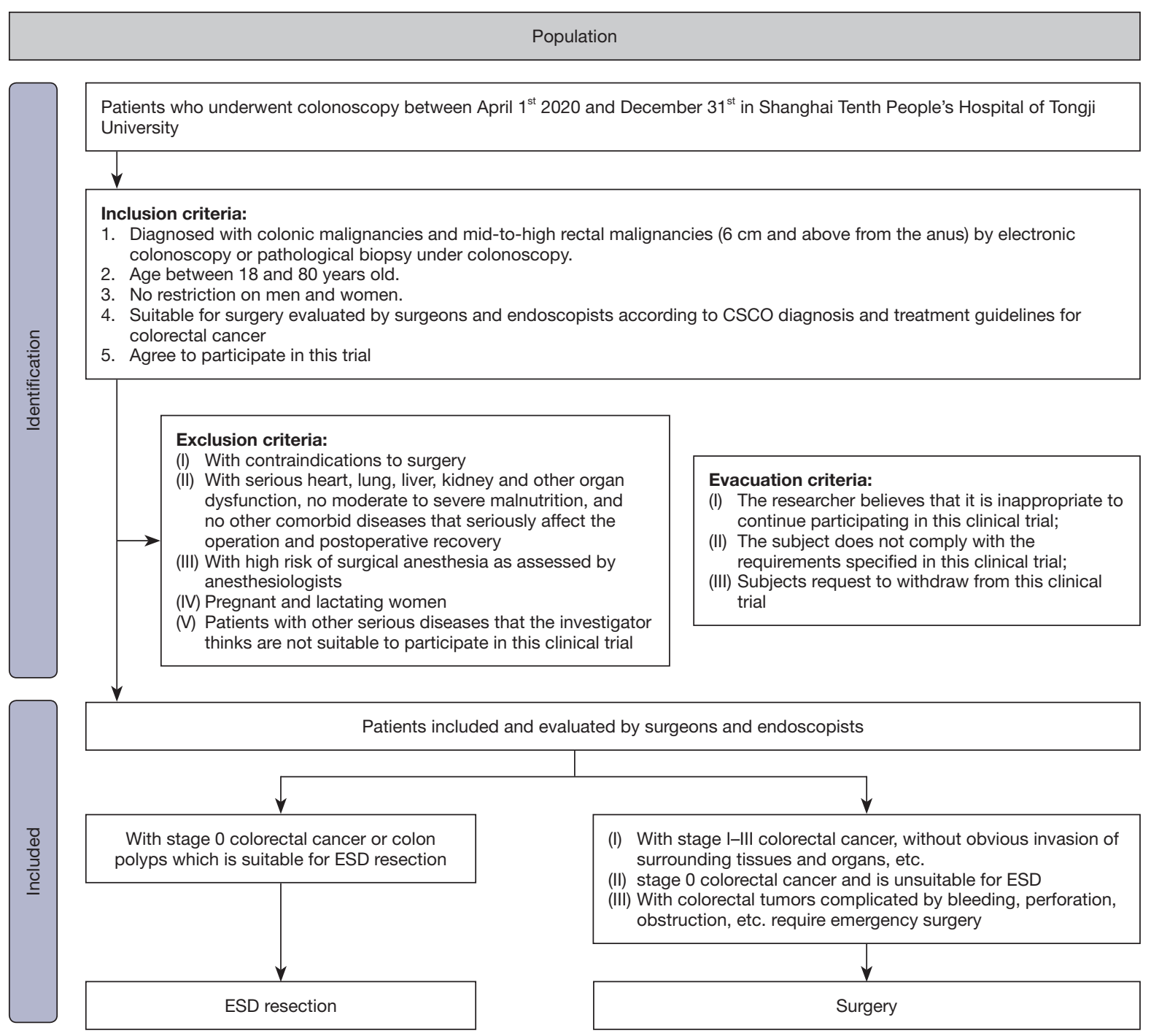

Figure 3 Inclusion criteria of the express group. CSCO, Chinese society of clinical oncology; ESD, endoscopic submucosal dissection.

of the four comparisons (Figure 6).

\section{Cost}

The mean TIC for each patient among all patients with CRC was 78,309.824 Chinese Yuan (Figure 7 and Table S2). Costs were slightly (but not significantly) lower in 2020 than in 2019, and the cost composition differed between the 2 years (Table 3). After controlling for other covariates (LOS and number of comorbidities), the cost of physician/nurse services for all 2020 patients (and for the 2020 patients treated by Dr. Liu's team) increased significantly compared with the costs for patients treated in $2019(\mathrm{P}<0.005)$ (Table
4). The only cost that markedly decreased from 2019 to 2020 was the consumables cost for patients treated by Dr. Liu's team $(27,609.098$ vs. $25,054.252, \mathrm{P}=0.023)$. The cost composition was similar for CCC and non-CCC patients, and only drug costs were significantly lower in the CCC express group than in the normal group $(70,276.564 \mathrm{vs}$. $74,773.793, \mathrm{P}=0.042)$. OOP expenses did not differ in any of the examined comparisons (Figure 8, Tables S3,S4).

\section{Discussion}

Presently, multidisciplinary cancer care is considered standard for the management of patients with cancer 


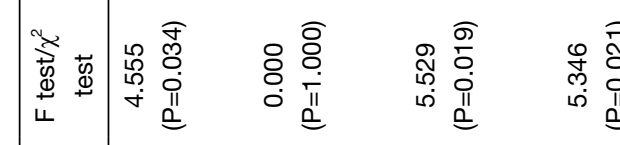

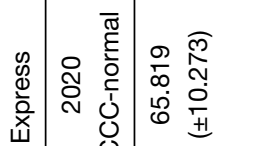

ш

品

ก.

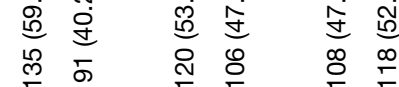

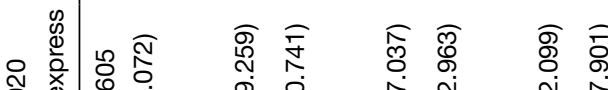

مิ

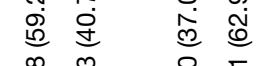

文

品 5

ले

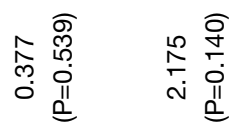

ㅇํㅇ

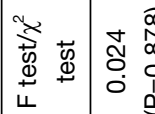

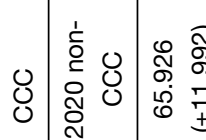

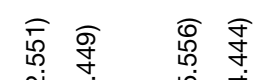

ํ.

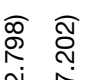

学 占

त्ष

递过

음

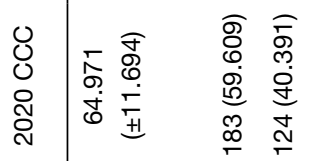

ठิ

तิ त్

竎

年

竞

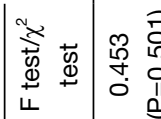

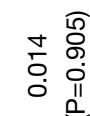

$\overline{\bar{\delta}}$

음

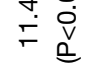

ㄱำ

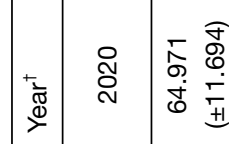

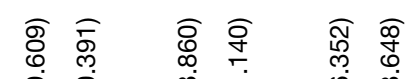

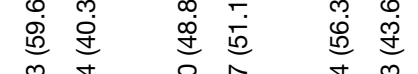

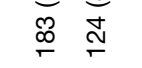

온

誉

ब)

ब

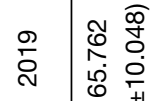

0
0
0

वे है

$\sqrt{10}$

党

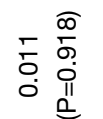

$\infty \widehat{\bar{\sigma}}$

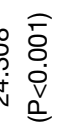

$\begin{array}{ll}\bar{\infty} & \widehat{\bar{o}} \\ \infty & 0 \\ \infty & 0 \\ \leftarrow & 0\end{array}$

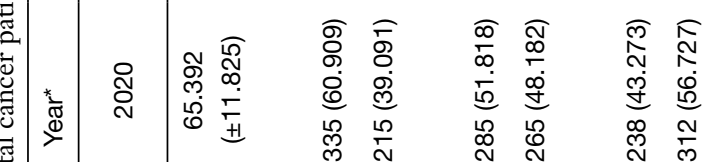

苟

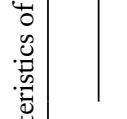

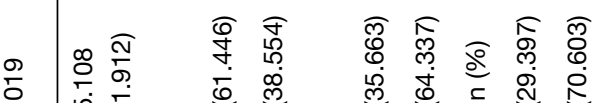

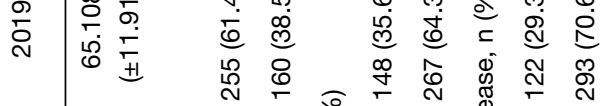
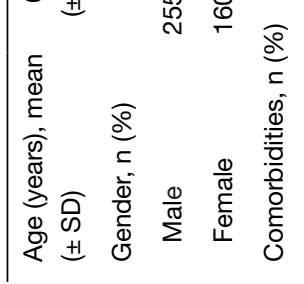

(a) 
Table 2 Covariance test for length of hospital stay

\begin{tabular}{|c|c|c|c|c|c|}
\hline \multirow{2}{*}{ Category } & \multicolumn{5}{|c|}{ LOS (days) } \\
\hline & Df. & Sum Sq. & Mean Sq & $\mathrm{F}$ value & $P$ \\
\hline \multicolumn{6}{|l|}{ Category 1} \\
\hline Sigmoid colectomy & 1 & 1,665 & 1,664 & 20.046 & $0.000^{\star \star \star}$ \\
\hline Year & 1 & 1 & 1 & 0.012 & 0.912 \\
\hline Residuals & 962 & 79,880 & 83 & - & - \\
\hline \multicolumn{6}{|l|}{ Category 2} \\
\hline Sigmoid colectomy & 1 & 805 & 805.0 & 10.726 & $0.001^{\star \star}$ \\
\hline Year & 1 & 144 & 143.7 & 1.914 & 0.167 \\
\hline Residuals & 434 & 32,573 & 75.1 & - & - \\
\hline \multicolumn{6}{|l|}{ Category 3} \\
\hline Sigmoid colectomy & 1 & 986 & 986.4 & 12.199 & $0.000^{\star \star \star}$ \\
\hline $\mathrm{CCC}$ & 1 & 758 & 758.2 & 9.377 & $0.002^{\star *}$ \\
\hline Residuals & 547 & 44,233 & 80.9 & - & - \\
\hline \multicolumn{6}{|l|}{ Category 4} \\
\hline Sigmoid colectomy & 1 & 752 & 752.3 & 11.81 & $0.000^{\star \star \star}$ \\
\hline Express & 1 & 2,113 & $2,112.6$ & 33.16 & $0.000^{\star \star \star}$ \\
\hline Residuals & 304 & 19,367 & 63.7 & - & - \\
\hline
\end{tabular}

Eight OLS regression models were used to identify the significant factors for predicting preoperative waiting time (models 1-4) and length of hospital stay (models 5-8). In these models, age, gender, household registration, insurance, comorbidities (pneumonia/respiratory tract infection, diabetes mellitus, kidney disease, and cirrhosis), surgical approach (left hemicolectomy, right hemicolectomy, transverse colectomy, sigmoid colectomy, or radical resection of rectum)-all examined variables except for the comparison variables of interest (i.e., year, CCC, and express)-were considered. The significance of the examined variables varied among the different models in terms of the two dependent variables (preoperative waiting time and length of hospital stay). No significant covariates were found in models $1-4$, while sigmoid colectomy was found to be significant after controlling for other variables in models $5-8$. The covariance test was performed only for significant comparison categories. ${ }^{* \star}, \mathrm{P}<0.01$; ${ }^{\star * *}, \mathrm{P}<0.001$. LOS, length of hospital stay; CCC, colorectal cancer center; OLS, ordinary least squares; Df, degree of freedom; Sq, squared. 

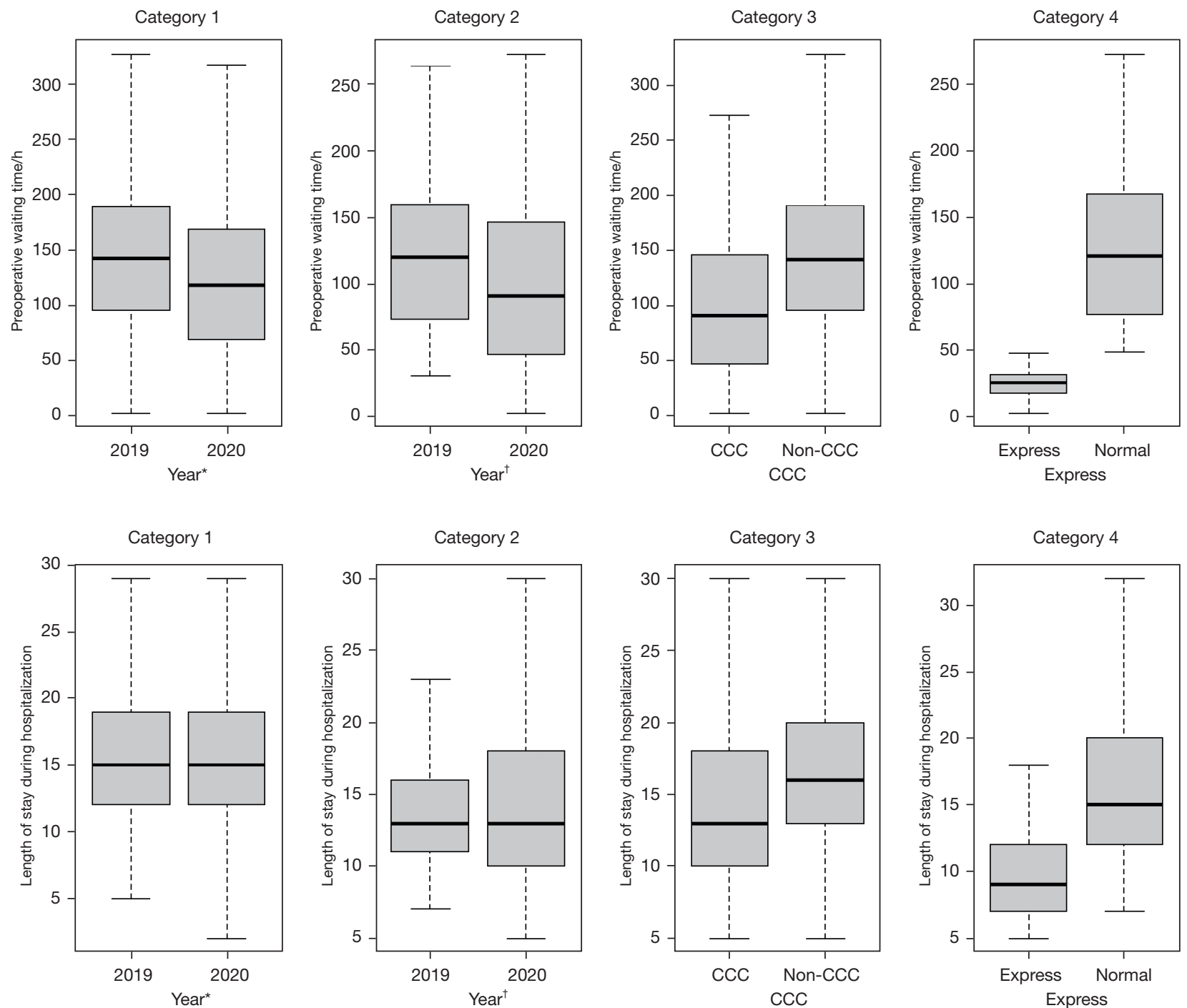

Figure 4 Comparisons of preoperative waiting time and length of hospital stay. (I) Comparison 1 is divided by year, including all CCPs, comparing the periods of March to December 2019 and March to December 2020. Comparison 2 included only patients treated by Dr. Z Liu's team. Comparison 3 compared CCC and non-CCC patients from March to December 2020. Comparison 4 compared express and non-express CCC patients. (II) PWT/hours: the ANOVA test results for comparisons $1-4$ were $\mathrm{F}=23.56(\mathrm{P}<0.001), \mathrm{F}=9.143$ ( $\mathrm{P}=0.003$ ), $\mathrm{F}=39.350(\mathrm{P}<0.001)$, and $\mathrm{F}=169.500(\mathrm{P}<0.001)$, respectively. (III) LOS/days: the ANOVA test results for comparisons $1-4$ were $\mathrm{F}=1.197$ $(\mathrm{P}=0.274), \mathrm{F}=0.424(\mathrm{P}=0.516), \mathrm{F}=10.850(\mathrm{P}<0.001)$, and $\mathrm{F}=35.740(\mathrm{P}<0.001)$, respectively. * comparison between the outcomes from March 1 to December 31, 2019, with those from March 1 to December 31, 2020; ${ }^{\dagger}$, the data from Dr. Liu's team for a comparison across the same two time periods (March 1 to December 31, 2019 vs. March 1 to December 31, 2020). CCPs, colorectal cancer patients; CCC, colorectal cancer center; PWT, preoperative waiting time; ANOVA, analysis of variance; LOS, length of hospital stay. 


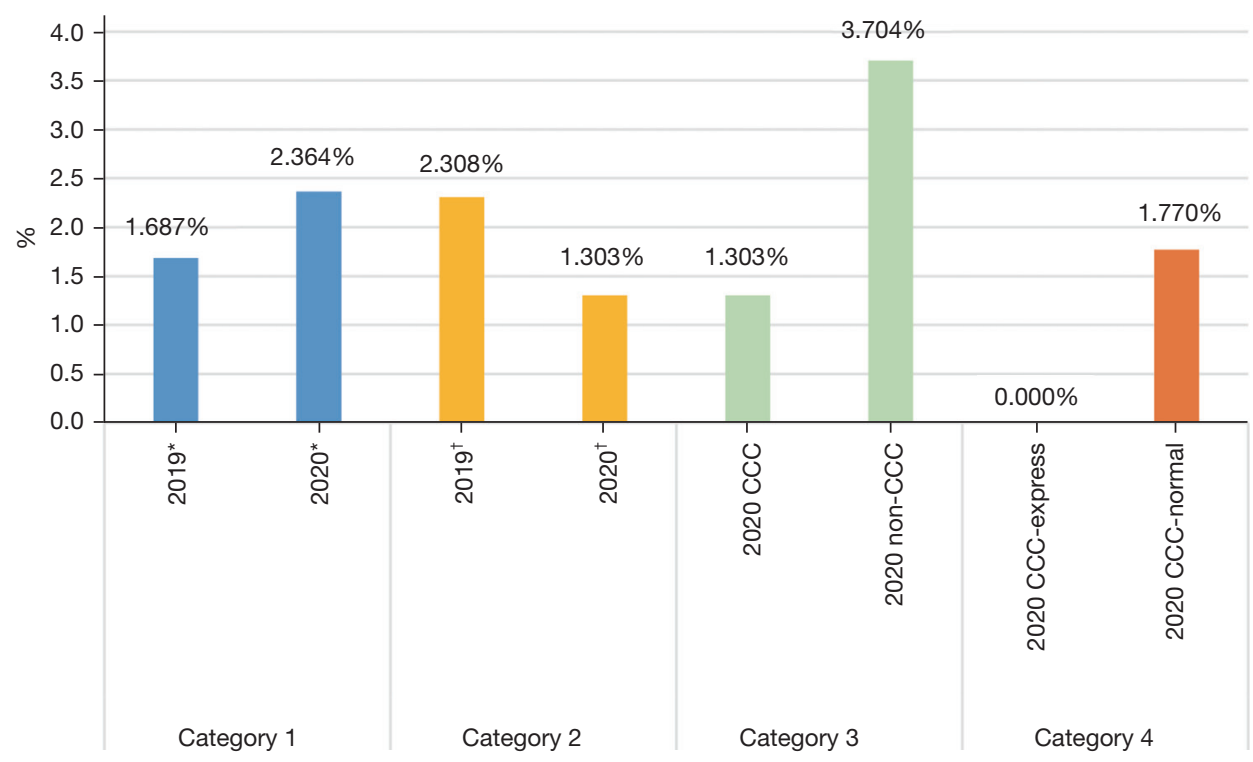

Figure 5 Percentages of inpatient colorectal cancer patients with postoperative complications. *, comparison between the outcomes from March 1 to December 31, 2019, with those from March 1 to December 31, 2020; ${ }^{\dagger}$, the data from Dr. Liu's team for a comparison across the same two time periods (March 1 to December 31, 2019 vs. March 1 to December 31, 2020). CCC, colorectal cancer center.

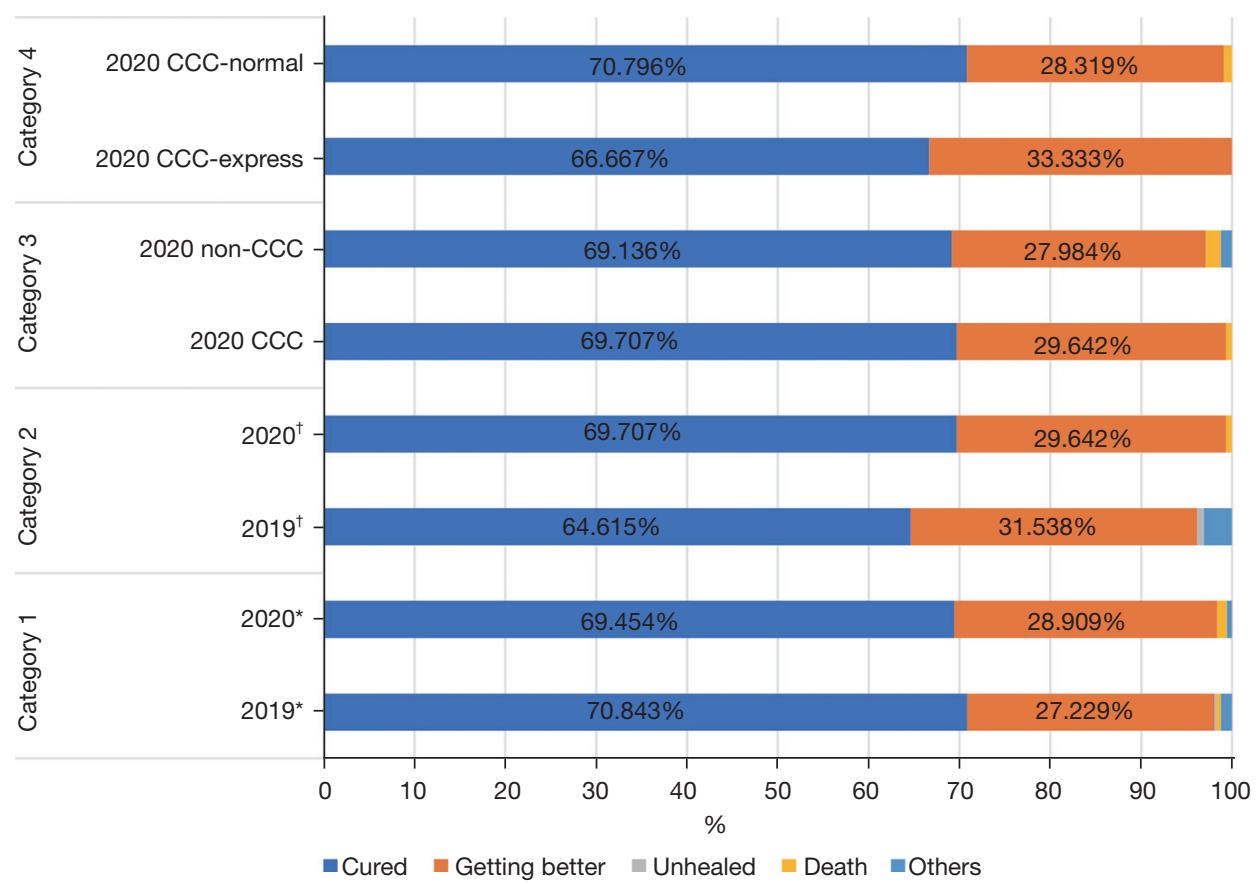

Figure 6 Surgical results of inpatient colorectal cancer patients. The test results of the four comparisons of surgery results were as follows: (I) comparison 1: $\chi^{2}=3.925, \mathrm{P}=0.416$; (II) comparison $2: \chi^{2}=13.111, \mathrm{P}=0.011$; (III) comparison $3: \chi^{2}=5.156, \mathrm{P}=0.161$; (IV) comparison 4: $\chi^{2}=1.368$, $\mathrm{P}=0.50 .^{*}$, comparison between the outcomes from March 1 to December 31, 2019, with those from March 1 to December 31, 2020; ${ }^{\dagger}$, the data from Dr. Liu's team for a comparison across the same two time periods (March 1 to December 31, 2019 vs. March 1 to December 31, 2020). CCC, colorectal cancer center. 

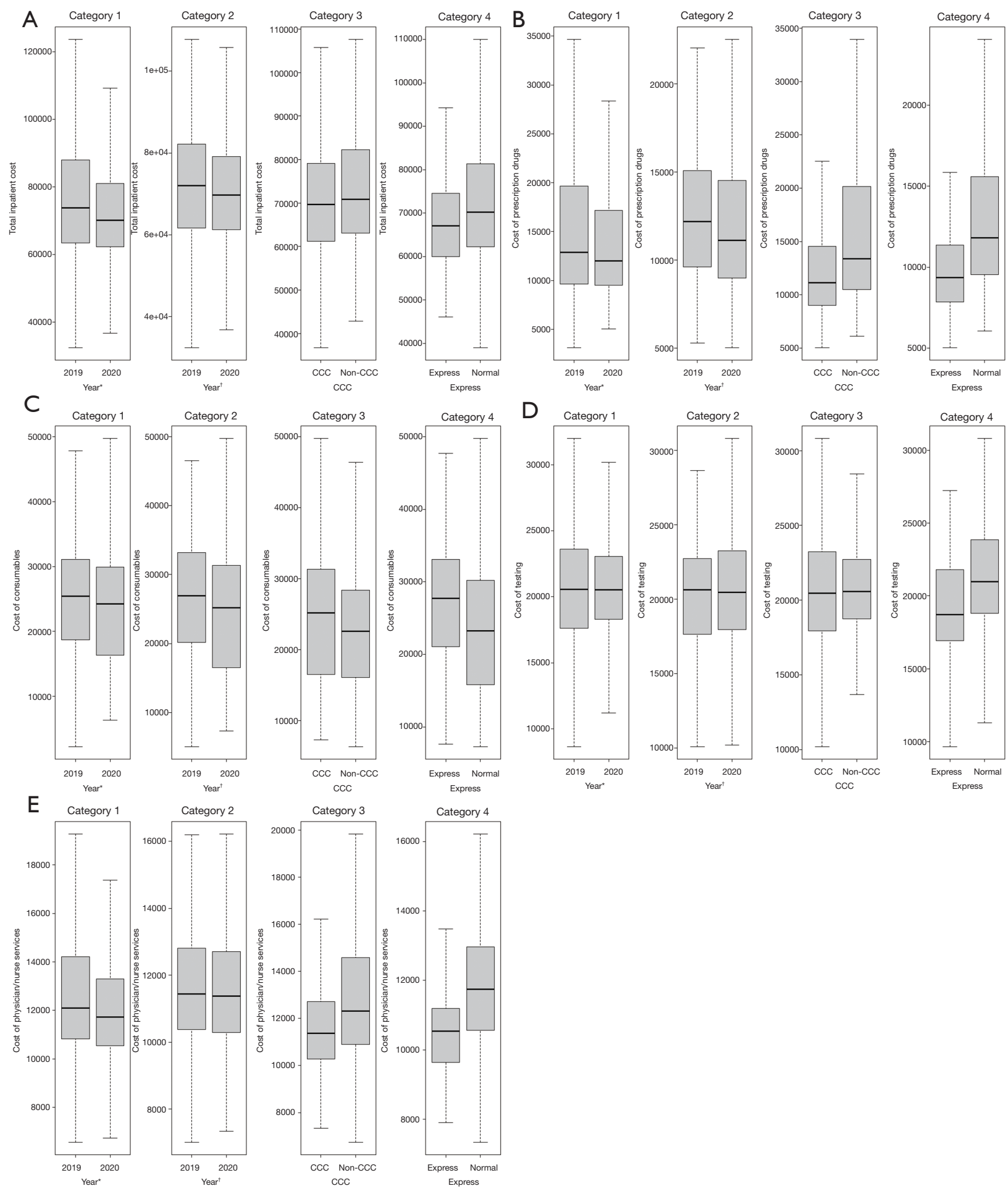

Figure 7 Composition of total inpatients cost. (A) Total inpatient cost; (B) cost of prescription drugs; (C) cost of consumables; (D) cost of testing; (E) cost of physician/nurse services. (I) Comparison 1 is divided by year, including all CCPs, comparing the periods of March to December 2019 and March to December 2020. Comparison 2 included only patients treated by Dr. Liu's team who entered the CCC. Comparison 3 compared CCC and non-CCC patients from March to December 2020. Comparison 4 compared express and non-express CCC patients. (II) Total inpatient cost: the ANOVA test results for comparisons 1-4 were $\mathrm{F}=2.630$ ( $\mathrm{P}=0.105), \mathrm{F}=1.048$ ( $\mathrm{P}=0.306), \mathrm{F}=5.921$ 
( $\mathrm{P}=0.153)$, and $\mathrm{F}=2.258(\mathrm{P}=0.134)$, respectively. (III) Cost of prescription drugs: the ANOVA test results for comparisons $1-4$ were $\mathrm{F}=1.501$ $(\mathrm{P}=0.221), \mathrm{F}=0.127(\mathrm{P}=0.721), \mathrm{F}=12.706(\mathrm{P}<0.001)$, and $\mathrm{F}=4.157(\mathrm{P}=0.042)$, respectively. (IV) Cost of consumables: the ANOVA test results for comparisons 1-4 were $\mathrm{F}=4.515(\mathrm{P}=0.033), \mathrm{F}=5.198(\mathrm{P}=0.023), \mathrm{F}=3.292(\mathrm{P}=0.070)$, and $\mathrm{F}=3.377(\mathrm{P}=0.067)$. (V) Cost of physician/nurse services: the ANOVA test results for comparisons $1-4$ were $\mathrm{F}=4.857(\mathrm{P}=0.028), \mathrm{F}=0.738(\mathrm{P}=0.397), \mathrm{F}=30.459(\mathrm{P}<0.001)$, and $\mathrm{F}=12.900$ $(\mathrm{P}<0.001)$. *, comparison between the outcomes from March 1 to December 31, 2019, with those from March 1 to December 31, 2020; ${ }^{\dagger}$, the data from Dr. Liu's team for a comparison across the same two time periods (March 1 to December 31, 2019 vs. March 1 to December 31, 2020). CCPs, colorectal cancer patients; CCC, colorectal cancer center; ANOVA, analysis of variance.

Table 3 Total inpatient costs and cost structure for inpatient colorectal cancer patients

\begin{tabular}{|c|c|c|c|c|c|c|c|c|c|c|c|c|}
\hline \multirow[t]{2}{*}{ Category } & \multirow[t]{2}{*}{$\mathrm{N}$} & \multirow{2}{*}{$\begin{array}{c}\text { Total inpatient } \\
\text { cost (CNY) }\end{array}$} & \multicolumn{2}{|c|}{ Prescription drugs } & \multicolumn{2}{|c|}{ Consumables } & \multicolumn{2}{|l|}{ Testing } & \multicolumn{2}{|c|}{$\begin{array}{c}\text { Physician/nurse } \\
\text { services }\end{array}$} & \multicolumn{2}{|l|}{ Other } \\
\hline & & & Cost (CNY) & $\%$ & Cost (CNY) & $\%$ & Cost (CNY) & $\%$ & Cost (CNY) & $\%$ & Cost (CNY) & $\%$ \\
\hline $2019^{\star}$ & 415 & $33,444,519.42$ & $7,622,227.18$ & 22.79 & $10,691,472.94$ & 31.97 & $8,706,706.50$ & 26.03 & $5,483,585.20$ & 16.40 & $940,527.60$ & 2.81 \\
\hline $2020^{\star}$ & 550 & $42,124,460.63$ & $9,106,536.58$ & 21.62 & $13,383,364.15$ & 31.77 & $11,439,432.50$ & 27.16 & $6,935,616.00$ & 16.46 & $1,259,511.40$ & 2.99 \\
\hline \multicolumn{13}{|l|}{ Category 2} \\
\hline $2019^{\dagger}$ & 130 & $9,951,954.20$ & $1,889,147.68$ & 18.98 & $3,589,182.72$ & 36.07 & $2,626,211.00$ & 26.39 & $1,587,000.00$ & 15.95 & $260,412.80$ & 2.62 \\
\hline $2020^{\dagger}$ & 307 & $22,591,279.00$ & $4,315,994.02$ & 19.10 & $7,691,655.43$ & 34.05 & $6,302,584.00$ & 27.90 & $3,651,450.75$ & 16.16 & $629,594.80$ & 2.79 \\
\hline Total & 437 & $32,543,233.20$ & $6,205,141.70$ & 19.07 & $11,280,838.15$ & 34.66 & $8,928,803.00$ & 27.44 & $5,238,450.75$ & 16.10 & $890,007.60$ & 2.73 \\
\hline $\begin{array}{l}2020 \\
\text { none-CCC }\end{array}$ & 243 & $19,533,181.63$ & $4,790,542.56$ & 24.53 & $5,691,708.72$ & 29.14 & $5,136,848.50$ & 26.30 & $3,284,165.25$ & 16.81 & $629,916.60$ & 3.22 \\
\hline Total & 550 & $42,124,460.63$ & $9,106,536.58$ & 21.62 & $13,383,364.15$ & 31.77 & $11,439,432.50$ & 27.16 & $6,935,616.00$ & 16.46 & $1,259,511.40$ & 2.99 \\
\hline \multicolumn{13}{|l|}{ Category 4} \\
\hline $\begin{array}{l}2020 \\
\text { CCC-express }\end{array}$ & 81 & $5,692,401.70$ & $967,980.58$ & 19.81 & $2,178,513.52$ & 32.62 & $1,542,784.00$ & 28.17 & $892,945.00$ & 16.32 & $110,178.60$ & 3.07 \\
\hline $\begin{array}{l}2020 \\
\text { CCC-normal }\end{array}$ & 226 & $16,898,877.30$ & $3,348,013.44$ & 17.00 & $5,513,141.91$ & 38.27 & $4,759,800.00$ & 27.10 & $2,758,505.75$ & 15.69 & $519,416.20$ & 1.94 \\
\hline Total & 307 & $22,591,279.00$ & $4,315,994.02$ & 19.10 & $7,691,655.43$ & 34.05 & $6,302,584.00$ & 27.90 & $3,651,450.75$ & 16.16 & $629,594.80$ & 2.79 \\
\hline
\end{tabular}

The cost of prescription drugs included the costs of Western medicine, Chinese patent medicine, and Chinese herbal medicine. The cost of consumables included the costs of implant materials, medical materials, intervention materials, dental materials, blood transfusions, and other medical consumables. The cost of testing included the costs of examination and tests. The cost of physician/nurse services included the costs of consultations, treatments, dental treatments, special surgical equipment, nursing care, and anesthesia. *, comparison between the outcomes from March 1 to December 31, 2019, with those from March 1 to December 31,$2020 ;{ }^{\dagger}$, the data from Dr. Liu's team for a comparison across the same two time periods (March 1 to December 31, 2019 vs. March 1 to December 31, 2020). $\mathrm{CCC}$, colorectal cancer center. 
Table 4 Covariance test for per capita hospitalization cost for inpatient colorectal cancer patients

\begin{tabular}{|c|c|c|c|c|c|c|c|c|c|c|}
\hline Category & \multicolumn{2}{|c|}{ TIC } & \multicolumn{2}{|c|}{ CPD } & \multicolumn{2}{|c|}{$\mathrm{CC}$} & \multicolumn{2}{|c|}{ CT } & \multicolumn{2}{|c|}{ CPNS } \\
\hline \multicolumn{11}{|l|}{ Category 1} \\
\hline LOS & - & - & - & - & 63.513 & $0.000^{\star \star \star}$ & - & - & 1055.421 & $0.000^{\star \star \star}$ \\
\hline $\mathrm{NC}$ & - & - & - & - & 0.062 & 0.803 & - & - & 1.545 & 0.214 \\
\hline \multicolumn{11}{|l|}{ Category 2} \\
\hline LOS & - & - & - & - & 24.109 & $0.000^{\star \star *}$ & - & - & 622.672 & $0.000^{\text {***}}$ \\
\hline $\mathrm{NC}$ & - & - & - & - & 3.340 & 0.068 & - & - & 4.164 & $0.042^{*}$ \\
\hline Year & - & - & - & - & 7.968 & $0.005^{\star *}$ & - & - & 18.991 & $0.000^{\star \star \star}$ \\
\hline $\mathrm{NC}$ & - & - & 12.417 & $0.000^{\star * \star}$ & - & - & - & - & - & - \\
\hline CCC & - & - & 3.444 & 0.064 & - & - & - & - & - & - \\
\hline \multicolumn{11}{|l|}{ Category 4} \\
\hline LOS & - & - & 268.177 & $0.000^{\star \star \star}$ & - & - & 84.051 & $0.000^{\star \star \star}$ & 325.355 & $0.000^{\star \star \star}$ \\
\hline $\mathrm{NC}$ & - & - & 1.886 & 0.170 & - & - & 14.653 & $0.000^{\star \star \star}$ & 2.997 & 0.085 \\
\hline Express & - & - & 8.074 & $0.004^{\star \star}$ & - & - & 0.113 & 0.737 & 1.083 & 0.299 \\
\hline
\end{tabular}

Sixteen OLS regression models were used to identify the significant factors for predicting total inpatient cost (models 1-4), total inpatient cost (models 5-8), CC (models 9-12), and cost of testing (models 13-16). In these models, age, gender, household registration, insurance, number of comorbidities, surgical approach (left hemicolectomy, right hemicolectomy, transverse colectomy, sigmoid colectomy, or radical resection of rectum), and length of hospital stay-all examined variables except for the comparison variables of interest (i.e., year, CCC, and express) - were considered. Length of hospital stay and number of comorbidities were identified as significant factors after controlling for other variables. The covariance test was performed only for significant comparison categories. ${ }^{*}, \mathrm{P}<0.05 ;{ }^{* *}, \mathrm{P}<0.01 ;{ }^{* \star *}, \mathrm{P}<0.001$. $\mathrm{TIC}$, total inpatient cost; CPD, cost of prescription drugs; CC, cost of consumables; CT, cost of testing; CPNS, cost of physician/nurse services; LOS, length of hospital stay; NC, number of comorbidities CCC, colorectal cancer center.

worldwide. Numerous medical centers headquartered in Europe and the United States, such as John Hopkins, MD Anderson, and Addenbrooke's Hospital, have established ideal MDT diagnostic and treatment processes for different cancers. Moreover, MDTs have become the standard approach in nearly $50 \%$ of hospitals in Germany, significantly improving the survival rate of cancer in the country through treatment in CCCs over more than 10 years (23). In particular, Germany has a cancer center certification program, where all participating organizations use the same standard data information system, allowing quality comparison and evaluation across different cancer centers, which differs from the situation in China (24). In the present study, we evaluated the effectiveness of the CCC in China in terms of time, quality, and cost.
For time, we observed that both PWT and LOS were shorter in the CCC. After controlling for the significant covariate of sigmoid colectomy, the time differences in the four examined comparisons remained significant. When the hospital first adopted the centralized management model to establish a CCC, an overall plan and layout design of the area for treating colorectal tumors were implemented, and the diagnosis and treatment procedures were set up on the same floor. Therefore, patients did not have to waste time moving back and forth between floors (25). A recent study has also shown that optimizing the hospital layout can increase efficiency and reduce the spread of COVID-19 during the pandemic (26). Secondly, in the CCC, a "onestop shop" was constructed for diagnosis and treatment, optimizing the combination of physicians and nurses to 

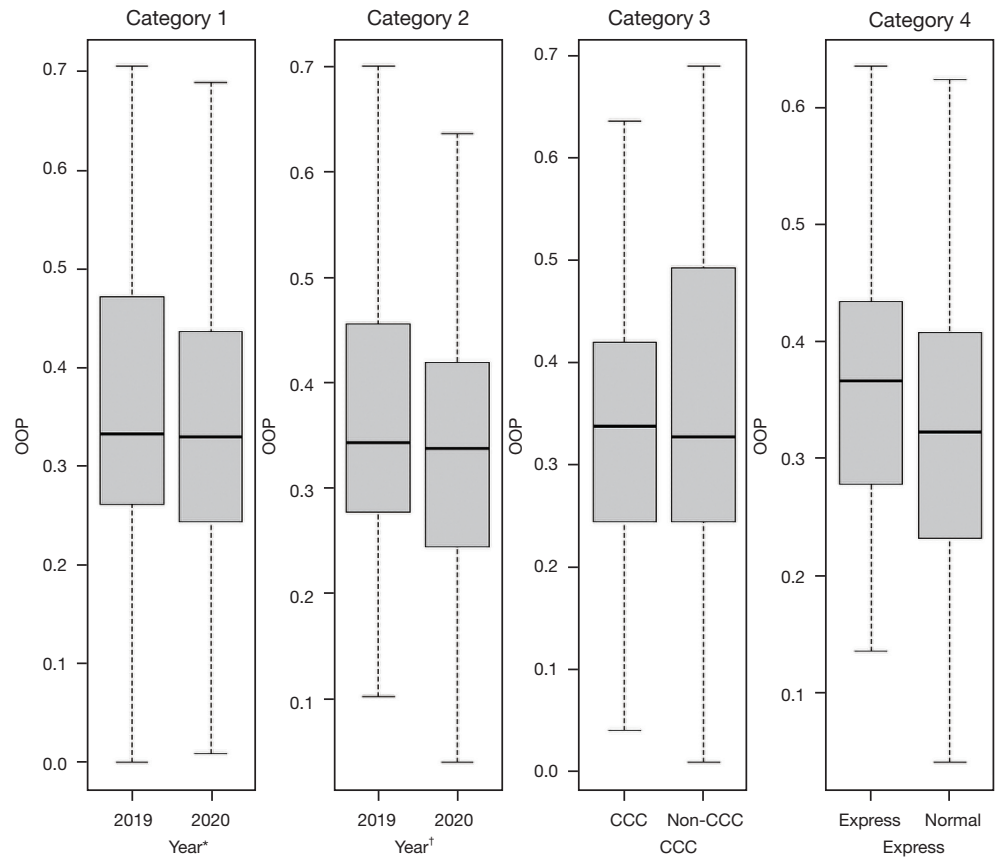

Figure 8 Per capita out-of-pocket cost for inpatient CCPs colorectal cancer patients. Four OLS regression models were applied to identify the significant factors for predicting OOP cost (models 1-4). In these models, age, gender, registered permanent residence, insurance, number of comorbidities, surgical approach (left hemicolectomy, right hemicolectomy, transverse colectomy, sigmoid colectomy, or radical resection of rectum) and LOS_all examined variables except for the comparison variables of interest (i.e., year, CCC, and express)—were considered. Age and insurance category were identified as significant factors after controlling for other variables. The covariance test was performed only for significant comparison categories. *, comparison between the outcomes from March 1 to December 31, 2019, with those from March 1 to December 31,$2020 ;{ }^{\dagger}$, the data from Dr. Liu's team for a comparison across the same two time periods (March 1 to December 31, 2019 vs. March 1 to December 31, 2020). CCPs, colorectal cancer patients; CCC, colorectal cancer center; OLS, ordinary least squares; OOP, out-of-pocket; LOS, length of hospital stay.

make the division of labor clearer and coordination between these health care professionals more reasonable (27). A previous survey confirmed that multidisciplinary clinics in CRC care can reduce patients' treatment time (28). The results of another study showed that MDT can increase the early detection rate of gastric cancer, which also reflects the role of MDTs in improving the efficiency of work (29). These results suggest that the centralized management model can help doctors and patients save time in the diagnosis and treatment of CRC.

Our study showed that, compared with the traditional treatment approach, patients with CRC who were treated in the CCC had consistent surgical quality as well as shortened PWT and LOS. The MDT approach involves multiple medical professionals providing integrated medical care. Integrated healthcare, which began modestly in the 1930s, has evolved into a mature model of healthcare that is quickly becoming the standard of care in many countries (30-32).
For example, in November 2010, The Netherlands set up an integrated healthcare standard for the management and prevention of obesity (33), and influential advocates in the United States and England have argued for financing and organizing healthcare based on the integrated healthcare delivery systems model (34). In the present study, integrated healthcare combining general surgery, pathology, radiology, psychology, and nursing was established in the CCC. This type of system allows patients to enjoy integrated care and improves the quality of surgery $(35,36)$. Furthermore, a performance appraisal plan was formulated for the CCC personnel, which has the potential to encourage personnel to take the initiative in order to better serve patients. It also has the potential to strengthen the trust between nurses and patients, and improve patients' initiative and satisfaction concerning cooperation with healthcare professionals, which greatly reduces the incidence of adverse events (37). These findings are consistent with prior research on a 
Veterans Affairs medical center, which showed that patients received increased quality of care, better access to care, and improved multidisciplinary treatment in CCCs (38). In addition, studies have shown that the MDT approach can improve the survival quality of patients with CRC and other types of tumors (39-42). The model examined in the present study realized the accumulation of medical resources, achieved the standardization of diagnosis and treatment procedures, and subsequently strengthened the incentive mechanism.

The per capita hospitalization cost of the colorectal cancer patients (CCPs)was reduced, and the patients' OOP also showed a downward trend. Under the integrated care approach, patients with CRC only need to register once, and they can enjoy expert service in five departments (the Chronic Disease Center, the Rehabilitation Department, the Psychology Department, the Nutrition Department, and the CCC). Integrating the health service content of multiple departments may avoid overlaps and redundancy in treatment items issued by different departments, thus reducing the cost of patient registration and testing (43). In the United States healthcare system, patients pay relatively high costs, and building a centralized management model to reduce the per capita cost of healthcare is a goal for government, in order to improve the system $(44,45)$. In the present study, before the establishment of the CCC, the average time from diagnosis to surgery for patients with CRC was 10-12 days. Following the implementation of the centralized management model, the time was reduced to 1-2 days owing to the optimization of the diagnosis and treatment process. For patients in good condition, surgery can be performed on the same day or the next day. Through this process, the patient may save the costs of retesting, prescription drugs, and services required due to treatment delays (46). The increasing health demands of the Chinese people and limited medical resources have led to an increase in patients' medical costs (47). The centralized management model can concentrate medical resources, better optimize the allocation of resources, and reduce the unnecessary waste of resources, which will in turn reduce the medical costs of inpatient CCPs. Patients' OOP costs will then be reduced as a result of the decrease in overall patient costs. Similarly, a prior study showed that an integrated training program was able to reduce the average hospitalization cost for patients with lung cancer (48).

The centralized management model was implemented in the hospital during the COVID-19 epidemic. The original reason for this implementation was to reduce the flow of personnel by establishing a centralized management system to facilitate safe diagnosis and treatment, avoid crossinfection in the hospital, and achieve the goal of epidemic prevention and control (49). Presently, the epidemic is in the normalization stage. This study evaluated the model and found that it was able to save time and money without reducing the quality of surgery, which is valuable and meaningful for the implementation of the model in the hospital. With the reform of public hospitals and the implementation of the zero-markup policy for drugs and consumables (50), the profit model of hospitals has gradually shifted from relying on drugs and consumables to strengthening internal control and improving the quality of medical services $(51,52)$. As far as hospitals are concerned, centralized management can increase profits by concentrating on medical resources and making better use of resources such as hospital beds. These changes can help with medical expenses savings for patients and improve the current medical situation at the societal level. This is a multi-profit model, and promoting the model is valuable.

However, this model also has some problems. For example, we found that the quality of surgery was not significantly improved. Furthermore, the CC still accounted for a large proportion of the total patient cost, and this proportion did not decline. However, with the full implementation of the zero-markup consumables policy, this proportion will definitely decrease in the future, and the increasing incentives for technological innovation and service quality among doctors will also improve the survival rates of patients. Also, completing preoperative preparations within 1 day is a challenge for both hospital administrators and clinicians, and identifying strategies that enable more patients who meet the necessary standards to benefit from the hospital's internal management is worthy of further discussion. The COVID-19 epidemic will not end soon, and epidemic prevention work will continue. It may be appropriate to recommend the centralized management model for application in suitable medical institutions and to advocate its promotion at the government level. The application of this model in the medical field should be further explored to optimize its function and efficiency, so as to enable multiple stake holders to better benefit from it.

Several limitations of this study should be considered. Firstly, the study's results are preliminary findings, and the centralized management model should be further tracked to evaluate its impact on effectiveness. Secondly, this was a pilot study in Shanghai, which is a developed city in China, 
so the findings of our study may not be generalizable to other geographic areas of the country. Thirdly, this research only evaluated the effectiveness of the centralization of care for CRC. In the future, the CRC for other cancers should be further explored. Fourthly, our hospital has treated 100 cases during the COVID-19 pandemic, and all of these patients have survived during a 1-year follow-up period; however, the long-term survival rate has not been considered. Those should be explored in the future studies, such as extending the follow-up time and evaluating the long-term survival rate to track this model.

\section{Conclusions}

This research evaluated a CCC established in the Shanghai Tenth People's Hospital of Tongji University for the centralized management for CRC during the COVID-19 epidemic. Despite the study limitations, we examined the efficiency of the centralized management model in CRC care in terms of time, cost, and quality. The study findings provide a reference for the construction of CCCs and the centralized management of CRC in China. However, there remains a need for further research that comprehensively assesses the effectiveness of the centralized management model and the factors that may affect patient outcomes.

\section{Acknowledgments}

We thank Jennifer Barrett, PhD, from Liwen Bianji, Edanz Editing China (https://www.liwenbianji.cn/ac), for basic language editing of a draft of this manuscript.

Funding: This study was sponsored by the Clinical Research Plan of SHDC (No. SHDC2020CR5006-002), the National Natural Science Foundation of China (No. 71804128, 71904145), the Special Funds for Fundamental Research Expenses of Central Universities (No. 22120200407), and the Personnel Development Plan of Shanghai Tenth People's Hospital of Tongji University (No. 2021SYPDRC014).

\section{Footnote}

Reporting Checklist: The authors have completed the STROBE reporting checklist. Available at https://atm. amegroups.com/article/view/10.21037/atm-21-7030/rc

Data Sharing Statement: Available at https://atm.amegroups. com/article/view/10.21037/atm-21-7030/dss
Conflicts of Interest: All authors have completed the ICMJE uniform disclosure form (available at https://atm. amegroups.com/article/view/10.21037/atm-21-7030/coif). The authors have no conflicts of interest to declare

Ethical Statement: The authors are accountable for all aspects of the work in ensuring that questions related to the accuracy or integrity of any part of the work are appropriately investigated and resolved. This study has been approved by the Ethics Committee of the Shanghai Tenth People's Hospital of Tongji University (No. SHSYIEC-4.1/20-272/01). Informed consent was obtained from all participants who took part in this study. All procedures performed in this study involving human participants were in accordance with the Declaration of Helsinki (as revised in 2013).

Open Access Statement: This is an Open Access article distributed in accordance with the Creative Commons Attribution-NonCommercial-NoDerivs 4.0 International License (CC BY-NC-ND 4.0), which permits the noncommercial replication and distribution of the article with the strict proviso that no changes or edits are made and the original work is properly cited (including links to both the formal publication through the relevant DOI and the license). See: https://creativecommons.org/licenses/by-nc-nd/4.0/.

\section{References}

1. Chapelle N, Martel M, Toes-Zoutendijk E, et al. Recent advances in clinical practice: colorectal cancer chemoprevention in the average-risk population. Gut 2020;69:2244-55.

2. Siegel RL, Miller KD, Fuchs HE, et al. Cancer Statistics, 2021. CA Cancer J Clin 2021;71:7-33.

3. Global Cancer data released in 2020:4.57 million new cancer cases in China [Web Page]. 2021-01-11. Available online: https://www.sohu.com/a/443816148_401010

4. Fligor SC, Wang S, Allar BG, et al. Gastrointestinal Malignancies and the COVID-19 Pandemic: Evidence-Based Triage to Surgery. J Gastrointest Surg 2020;24:2357-73.

5. Kim CH, Huh JW, Kim HR, et al. CpG island methylator phenotype is an independent predictor of survival after curative resection for colorectal cancer: A prospective cohort study. J Gastroenterol Hepatol 2017;32:1469-74.

6. Raj Kumar B, Pandey D, Rohila J, et al. An observational study of the demographic and treatment changes in a 


\section{Page 18 of 19}

tertiary colorectal cancer center during the COVID-19 pandemic. J Surg Oncol 2020;122:1271-5.

7. Maringe C, Spicer J, Morris $M$, et al. The impact of the COVID-19 pandemic on cancer deaths due to delays in diagnosis in England, UK: a national, population-based, modelling study. Lancet Oncol 2020;21:1023-34.

8. Neal RD, Tharmanathan P, France B, et al. Is increased time to diagnosis and treatment in symptomatic cancer associated with poorer outcomes? Systematic review. $\mathrm{Br} \mathrm{J}$ Cancer 2015;112 Suppl 1:S92-107.

9. Loveday C, Sud A, Jones ME, et al. Prioritisation by FIT to mitigate the impact of delays in the 2-week wait colorectal cancer referral pathway during the COVID-19 pandemic: a UK modelling study. Gut 2021;70:1053-60.

10. Kutikov A, Weinberg DS, Edelman MJ, et al. A War on Two Fronts: Cancer Care in the Time of COVID-19. Ann Intern Med 2020;172:756-8.

11. Grasselli G, Zangrillo A, Zanella A, et al. Baseline Characteristics and Outcomes of 1591 Patients Infected With SARS-CoV-2 Admitted to ICUs of the Lombardy Region, Italy. JAMA 2020;323:1574-81.

12. Chu E. Treatment of Colorectal Cancer and Other GI Cancers in the COVID-19 Pandemic. Clin Colorectal Cancer 2020;19:145.

13. Rutter MD, Brookes M, Lee TJ, et al. Impact of the COVID-19 pandemic on UK endoscopic activity and cancer detection: a National Endoscopy Database Analysis. Gut 2021;70:537-43.

14. Dekker E, Tanis PJ, Vleugels JLA, et al. Colorectal cancer. Lancet 2019;394:1467-80.

15. Anania G, Resta G, Marino S, et al. Treatment of Colorectal Cancer: a Multidisciplinary Approach. J Gastrointest Cancer 2019;50:458-68.

16. Vonlanthen R, Lodge P, Barkun JS, et al. Toward a Consensus on Centralization in Surgery. Ann Surg 2018;268:712-24.

17. Christiansen T, Vrangbæk K. Hospital centralization and performance in Denmark-Ten years on. Health Policy 2018;122:321-8.

18. Song P, Wu Q, Huang Y. Multidisciplinary team and team oncology medicine research and development in China. Biosci Trends 2010;4:151-60.

19. Sun X, Jiang K, Chen J, et al. A systematic review of maggot debridement therapy for chronically infected wounds and ulcers. Int J Infect Dis 2014;25:32-7.

20. Circular on the publication of the first list of pilot hospitals for multi-disciplinary diagnosis and treatment of cancer (digestive system) [Web Page]. 2018-12-04.
Liu et al. Evaluation of a CCC model during the COVID-19 epidemic

Available online: http://www.nhc.gov.cn/cms-search/xxgk/ getManuscriptXxgk.htm?id=eb2e49cbe504464790d922a3f $8 \mathrm{e} 7 \mathrm{a} 1 \mathrm{~d} 2$

21. Vahdat V, Namin A, Azghandi R, et al. Improving patient timeliness of care through efficient outpatient clinic layout design using data-driven simulation and optimisation. Health Syst (Basingstoke) 2019;8:162-83.

22. Ferenc J. Assessing the current and future state of health care design [Web Page]. Retrieved August 21, 2018. Available online: https://www.hfmmagazine.com/ articles/2312-assessing-the-current-future-state-of-healthcare-design

23. Schmidt CG. Construction and centralisation of oncologic institutions of Essen hospitals at a central tumor center (West German tumor center) and comprehensive cancer center (CCC). Strahlentherapie 1978;154:161-8.

24. Kowalski C, Graeven U, von Kalle C, et al. Shifting cancer care towards Multidisciplinarity: the cancer center certification program of the German cancer society. BMC Cancer 2017;17:850.

25. Seelye A. Hospital ward layout and nurse staffing. J Adv Nurs 1982;7:195-201.

26. Zhang Q, Cheng S, Cheng Q. Experience summary of a COVID-19 designated community hospital and its operation model. Panminerva Med 2020. [Epub ahead of print].

27. Fleissig A, Jenkins V, Catt S, et al. Multidisciplinary teams in cancer care: are they effective in the UK? Lancet Oncol 2006;7:935-43.

28. Kozak VN, Khorana AA, Amarnath S, et al. Multidisciplinary Clinics for Colorectal Cancer Care Reduces Treatment Time. Clin Colorectal Cancer 2017;16:366-71.

29. Di L, Wu H, Zhu R, et al. Multi-disciplinary team for early gastric cancer diagnosis improves the detection rate of early gastric cancer. BMC Gastroenterol 2017;17:147.

30. Tham TY, Tran TL, Prueksaritanond S, et al. Integrated health care systems in Asia: an urgent necessity. Clin Interv Aging 2018;13:2527-38.

31. Morris AM. Putting the integration into integrated health care systems. J Clin Oncol 2015;33:821-2.

32. Wei YJ, Hsieh CF, Huang YT, et al. The influence of integrated geriatric outpatient clinics on the health care utilization of older people. BMC Geriatr 2020;20:379.

33. Seidell JC, Halberstadt J, Noordam H, et al. An integrated health care standard for the management and prevention of obesity in The Netherlands. Fam Pract 2012;29 Suppl 1:i153-6. 
34. Bevan G, Janus K. Why hasn't integrated health care developed widely in the United States and not at all in England? J Health Polit Policy Law 2011;36:141-64.

35. Marshall CL, Balentine CJ, Robinson CN, et al. A multidisciplinary cancer center maximizes surgeons' impact. J Surg Res 2011;171:15-22.

36. Tagliaferri L, Garganese G, D'Aviero A, et al. Multidisciplinary personalized approach in the management of vulvar cancer - the Vul.Can Team experience. Int J Gynecol Cancer 2020;30:932-8.

37. Wu Y, Li S, Patel A, et al. Effect of a Quality of Care Improvement Initiative in Patients With Acute Coronary Syndrome in Resource-Constrained Hospitals in China: A Randomized Clinical Trial. JAMA Cardiol 2019;4:418-27.

38. Wilks JA, Liebig C, Tasleem SH, et al. Rectal cancer patients benefit from implementation of a dedicated colorectal cancer center in a Veterans Affairs Medical Center. Am J Surg 2009;198:100-4.

39. Yao HW, Xiu DR, Fu W, et al. A clinical study on multidisciplinary team and surgery for resectable colorectal cancer with liver metastases. Zhonghua Wai Ke Za Zhi 2012;50:961-5.

40. Yopp AC, Mansour JC, Beg MS, et al. Establishment of a multidisciplinary hepatocellular carcinoma clinic is associated with improved clinical outcome. Ann Surg Oncol 2014;21:1287-95.

41. Manzano JG, Park A, Lin H, et al. Demonstrating value: association of cost and quality outcomes with implementation of a value-driven oncology-hospitalist inpatient collaboration for patients with lung cancer. BMJ Open Qual 2019;8:e000381.

42. Hung HY, Tseng YH, Chao HS, et al. Multidisciplinary team discussion results in survival benefit for patients with stage III non-small-cell lung cancer. PLoS One 2020;15:e0236503.

Cite this article as: Liu R, Yu X, Zeng X, Wang Z, Zhou D, Liu Z, Liu F, Zhuang C, Zhuang Y, Zhang J, Niu P, Yan B, Zhi R, Li J, Huang J, Qin H. Preliminary evaluation of a new initiative to centralize colorectal cancer care during the COVID-19 epidemic in Shanghai, China: a retrospective study. Ann Transl Med 2022;10(2):94. doi: 10.21037/atm-21-7030
43. Willenbring ML, Olson DH. A randomized trial of integrated outpatient treatment for medically ill alcoholic men. Arch Intern Med 1999;159:1946-52.

44. Aaron HJ, Schwartz WB. Hospital cost control: a bitter pill to swallow. Harv Bus Rev 1985;63:160-7.

45. Berwick DM, Nolan TW, Whittington J. The triple aim: care, health, and cost. Health Aff (Millwood) 2008;27:759-69.

46. Ayala MA, Yencha MW. Outpatient Thyroid Surgery in a Low-Surgical Volume Hospital. World J Surg 2015;39:2253-8.

47. Chai P, Zhang Y, Zhou M, et al. Health system productivity in China: a comparison of pre- and post-2009 healthcare reform. Health Policy Plan 2020;35:257-66.

48. Zou J, Xu X, Wang D, et al. The impacts of the multidisciplinary team model on the length of stay and hospital expenses of patients with lung cancer. Zhonghua Jie He He Hu Xi Za Zhi 2015;38:370-4.

49. Xu X, Yang YQ, Jiang YC, et al. Application and thinking of health standards related to medical care and health information in prevention and control of COVID-19. Zhonghua Liu Xing Bing Xue Za Zhi 2020;41:1765-71.

50. Council. TCCotCPoCatS. The opinion of on deepening the reform of the medical and health system [Web Page].2009-3-17. Available online: http://www.gov.cn/ jrzg/2009

51. Evans JM, Baker GR, Berta W, et al. The evolution of integrated health care strategies. Adv Health Care Manag 2013;15:125-61.

52. Deng J, Tian H, Guo Y, et al. A retrospective and prospective assessment of the zero-markup drug reform in China from the perspective of policy diffusion. Int J Health Plann Manage 2018;33:e918-29.

(English Language Editor: A. Kassem) 


\section{Supplementary}

Table S1 Preoperative waiting time and length of hospital stay across the comparison groups

\begin{tabular}{|c|c|c|c|c|c|c|c|c|c|c|c|}
\hline Category & $\mathrm{N}$ & \multicolumn{5}{|c|}{ Preoperative waiting time (hours) } & \multicolumn{5}{|c|}{ Length of staying (days) } \\
\hline \multicolumn{12}{|l|}{ Category 1} \\
\hline $2019^{*}$ & 415 & 158.518 & 1.823 & $1,031.621$ & 106.317 & $23.56(\mathrm{P}<0.001)$ & 15.400 & 5.000 & 103.000 & 8.836 & $1.197(P=0.274)$ \\
\hline $2020^{*}$ & 550 & 127.681 & 2.083 & 718.653 & 90.659 & & 15.182 & 8.000 & 36.000 & 7.563 & \\
\hline \multicolumn{12}{|l|}{ Category 2} \\
\hline $2019^{\dagger}$ & 130 & 133.060 & 31.043 & 507.404 & 83.703 & $9.143(P=0.003)$ & 14.969 & 7.000 & 103.000 & 9.342 & $0.424(P=0.516)$ \\
\hline $2020^{\dagger}$ & 307 & 106.822 & 2.653 & 498.095 & 82.597 & & 15.567 & 5.000 & 66.000 & 8.524 & \\
\hline Total & 437 & 114.628 & 2.653 & 5.074 & 83.697 & & 15.389 & 5.000 & 103.000 & 8.768 & \\
\hline 2020 none-CCC & 243 & 154.035 & 2.083 & 718.653 & 93.647 & & 18.132 & 2.000 & 93.000 & 9.718 & \\
\hline Total & 550 & 127.681 & 2.083 & 718.653 & 90.659 & & 16.700 & 2.000 & 103.000 & 9.151 & \\
\hline \multicolumn{12}{|l|}{ Category 4} \\
\hline 2020 CCC-express & 81 & 24.502 & 2.653 & 47.421 & 13.566 & $169.500(P<0.001)$ & 10.963 & 5.000 & 43.000 & 7.476 & $35.740(P<0.001)$ \\
\hline 2020 CCC-normal & 226 & 136.326 & 48.170 & 498.095 & 76.804 & & 17.217 & 7.000 & 66,000 & 8.281 & \\
\hline Total & 307 & 106.822 & 2.653 & 498.095 & 82.597 & & 15.567 & 5.000 & 66.000 & 8.524 & \\
\hline
\end{tabular}

*, comparison between the outcomes from March 1 to December 31, 2019, with those from March 1 to December 31,$2020 ;{ }^{\dagger}$, the data from Dr. Liu's team for a comparison across the same two time periods (March 1 to December 31, 2019 vs. March 1 to December 31, 2020). ANOVA, analysis of variance; SD, standard deviation; CCC, colorectal cancer center. 
Table S2 Per capita hospitalization cost for inpatient colorectal cancer patients

\begin{tabular}{|c|c|c|c|c|c|c|c|c|c|c|c|c|c|c|c|c|}
\hline \multirow[b]{2}{*}{ Category } & \multirow[b]{2}{*}{$\mathrm{N}$} & \multicolumn{3}{|c|}{ Total inpatient cost } & \multicolumn{3}{|c|}{ Cost of prescription drugs } & \multicolumn{3}{|c|}{ Cost of consumables } & \multicolumn{3}{|c|}{ Cost of testing } & \multicolumn{3}{|c|}{ Cost of physician/nurse services } \\
\hline & & Mean & SD & $\begin{array}{c}\text { ANOVA F } \\
\text { test }\end{array}$ & Mean & SD & $\begin{array}{c}\text { ANOVA F } \\
\text { test }\end{array}$ & Mean & SD & $\begin{array}{c}\text { ANOVA F } \\
\text { test }\end{array}$ & Mean & SD & $\begin{array}{c}\text { ANOVA F } \\
\text { test }\end{array}$ & Mean & SD & $\begin{array}{c}\text { ANOVA F } \\
\text { test }\end{array}$ \\
\hline \multicolumn{17}{|l|}{ Category 1} \\
\hline $2019^{*}$ & 415 & $80,589.203$ & $43,926.699$ & \multirow{3}{*}{$\begin{array}{c}2.630 \\
(P=0.105)\end{array}$} & $18,366.812$ & $27,155.279$ & \multirow{3}{*}{$\begin{array}{c}1.501 \\
(P=0.221)\end{array}$} & $25,762.585$ & $10,140.882$ & \multirow{3}{*}{$\begin{array}{c}4.515 \\
(P=0.033)\end{array}$} & $20,980.016$ & $7,542.049$ & \multirow{3}{*}{$\begin{array}{c}0.162 \\
(P=0.686)\end{array}$} & $13,213.458$ & $4,986.698$ & \multirow{3}{*}{$\begin{array}{c}4.857 \\
(P=0.028)\end{array}$} \\
\hline $2020^{\star}$ & 550 & $76,589.928$ & $32,671.914$ & & $16,557.339$ & $18,673.929$ & & $24,333.389$ & $10,493.963$ & & $20,798.968$ & $6,369.950$ & & $12,610.211$ & $3,511.510$ & \\
\hline Total & 965 & $78,309.824$ & $37,954.042$ & & $17,335.506$ & $22,717.522$ & & $24,948.018$ & $10,362.493$ & & $20,876.828$ & $6,895.296$ & & $12,869.639$ & $4,217.951$ & \\
\hline \multicolumn{17}{|l|}{ Category 2} \\
\hline $2019^{\dagger}$ & 130 & $76,553.494$ & $36,233.173$ & \multirow{3}{*}{$\begin{array}{c}1.048 \\
(P=0.306)\end{array}$} & $14,531.905$ & $16,052.412$ & \multirow{3}{*}{$\begin{array}{c}0.127 \\
(P=0.721)\end{array}$} & $27,609.098$ & $11,079.187$ & \multirow{3}{*}{$\begin{array}{c}5.198 \\
(P=0.023)\end{array}$} & $20,201.623$ & $7,153.474$ & \multirow{3}{*}{$\begin{array}{c}0.255 \\
(P=0.613)\end{array}$} & $12,207.692$ & $5,015.475$ & \multirow{3}{*}{$\begin{array}{c}0.738 \\
(P=0.397)\end{array}$} \\
\hline $2020^{\dagger}$ & 307 & $73,587.228$ & $23,158.989$ & & $14,058.612$ & $10,902.085$ & & $25,054.252$ & $10,548.662$ & & $20,529.589$ & $5,752.880$ & & $11,893.976$ & $2,589.622$ & \\
\hline Total & 437 & $74,469.641$ & $27,689.297$ & & $14,199.409$ & $12,637.404$ & & $25,814.275$ & $10,760.165$ & & $20,432.025$ & $6,196.014$ & & $11,987.301$ & $3,488.533$ & \\
\hline \multicolumn{17}{|l|}{ Category 3} \\
\hline 2020 CCC & 307 & $73,587.228$ & $23,158.989$ & \multirow{3}{*}{$\begin{array}{c}5.921 \\
(P=0.153)\end{array}$} & $14,058.612$ & $10,902.085$ & \multirow{3}{*}{$\begin{array}{c}12.706 \\
(P=0.000)\end{array}$} & $25,054.252$ & $10,548.662$ & \multirow{3}{*}{$\begin{array}{c}3.292 \\
(P=0.070)\end{array}$} & $20,529.589$ & $5,752.880$ & \multirow{3}{*}{$\begin{array}{c}1.243 \\
(P=0.265)\end{array}$} & $11,893.976$ & $2,589.622$ & \multirow{3}{*}{$\begin{array}{c}30.459 \\
(P<0.001)\end{array}$} \\
\hline 2020 none-CCC & 243 & $80,383.463$ & $41,443.358$ & & $19,714.167$ & $24,957.541$ & & $23,422.669$ & $10,374.530$ & & $21,139.294$ & $7,070.684$ & & $13,515.083$ & $4,245.085$ & \\
\hline Total & 550 & $76,589.928$ & $32,671.913$ & & $16,557.339$ & $18,673.929$ & & $24,333.389$ & $10,493.964$ & & $20,798.968$ & $6,369.950$ & & $12,610.211$ & $3,511.510$ & \\
\hline \multicolumn{17}{|l|}{ Category 4} \\
\hline 2020 CCC-express & 81 & $70,276.564$ & $20,464.528$ & \multirow{3}{*}{$\begin{array}{c}2.258 \\
(P=0.134)\end{array}$} & $11,950.378$ & $9,978.759$ & \multirow{3}{*}{$\begin{array}{c}4.157 \\
(P=0.042)\end{array}$} & $26,895.229$ & $8,022.206$ & \multirow{3}{*}{$\begin{array}{c}3.377 \\
(P=0.067)\end{array}$} & $19,046.716$ & $5,214.601$ & \multirow{3}{*}{$\begin{array}{c}7.465 \\
(P=0.007)\end{array}$} & $11,024.012$ & $2,537.594$ & \multirow{3}{*}{$\begin{array}{c}12.900 \\
(P<0.001)\end{array}$} \\
\hline 2020 CCC-normal & 226 & $74,773.793$ & $23,982.394$ & & $14,814.219$ & $11,138.455$ & & $24,394.433$ & $11,260.264$ & & $21,061.062$ & $5,853.754$ & & $12,205.778$ & $2,541.787$ & \\
\hline Total & 307 & $73,587.228$ & $23,158.989$ & & $14,058.612$ & $10,902.085$ & & $25,054.252$ & $10,548.662$ & & $20,529.589$ & $5,752.880$ & & $11,893.976$ & $2,589.622$ & \\
\hline
\end{tabular}

1 to December 31, 2019 vs. March 1 to December 31, 2020). ANOVA, analysis of variance; SD, standard deviation; CCC, colorectal cancer center. 
Table S3 Per capita out-of-pocket cost for inpatient colorectal cancer patients

\begin{tabular}{|c|c|c|c|c|c|}
\hline Category & $\mathrm{N}$ & $\mathrm{TIC}$ & OOP & SD & ANOVA F test \\
\hline $2019^{*}$ & 415 & $33,444,519.42$ & $44.087 \%$ & 0.28499 & $3.360(P=0.067)$ \\
\hline $2020^{\star}$ & 550 & $42,124,460.63$ & $40.877 \%$ & 0.25689 & \\
\hline Total & 965 & $75,568,980.05$ & $42.257 \%$ & 0.26966 & \\
\hline $2019^{\dagger}$ & 130 & $9,951,954.20$ & $42.803 \%$ & 0.26131 & $2.292(P=0.131)$ \\
\hline $2020^{\dagger}$ & 307 & $22,591,279.00$ & $38.958 \%$ & 0.23443 & \\
\hline Total & 437 & $32,543,233.20$ & $40.102 \%$ & 0.24307 & \\
\hline \multicolumn{6}{|l|}{ Category 3} \\
\hline Total & 550 & $42,124,460.63$ & $40.876 \%$ & 0.256892 & \\
\hline \multicolumn{6}{|l|}{ Category 4} \\
\hline 2020 CCC-express & 81 & $5,692,401.70$ & $42.668 \%$ & 0.24788 & $2.772(\mathrm{P}=0.096)$ \\
\hline 2020 CCC-normal & 226 & $16,898,877.30$ & $37.628 \%$ & 0.22852 & \\
\hline Total & 307 & $22,591,279.00$ & $38.958 \%$ & 0.23443 & \\
\hline
\end{tabular}

*, comparison between the outcomes from March 1 to December 31, 2019, with those from March 1 to December 31,$2020 ;{ }^{\dagger}$, the data from Dr. Liu's team for a comparison across the same two time periods (March 1 to December 31, 2019 vs. March 1 to December 31 , 2020). TIC, total inpatient cost; OOP, out-of-pocket; ANOVA, analysis of variance; SD, standard deviation; CCC, colorectal cancer center. 
Table S4 Covariance tests of out-of-pocket cost for inpatient colorectal cancer patients

\begin{tabular}{|c|c|c|}
\hline Category & F value & $\mathrm{P}$ \\
\hline \multicolumn{3}{|l|}{ Category 1} \\
\hline Insurance & - & - \\
\hline Age & - & - \\
\hline Year & - & - \\
\hline \multicolumn{3}{|l|}{ Category 2} \\
\hline Insurance & - & - \\
\hline Age & - & - \\
\hline Year & - & - \\
\hline \multicolumn{3}{|l|}{ Category 3} \\
\hline Insurance & 936.161 & $<0.001^{\star \star \star}$ \\
\hline Age & 4.293 & $0.039^{*}$ \\
\hline $\mathrm{CCC}$ & 2.796 & 0.095 \\
\hline \multicolumn{3}{|l|}{ Category 4} \\
\hline Insurance & - & - \\
\hline Age & - & - \\
\hline Express & - & - \\
\hline
\end{tabular}

${ }^{\star}, \mathrm{P}<0.05 ;{ }^{\star \star \star}, \mathrm{P}<0.001 . \mathrm{CCC}$, colorectal cancer center. 